\title{
DNA Probe modified with 3-iron bis(dicarbollide) for Electrochemical Determination of DNA Sequence of Avian Influenza Virus H5N1
}

Iwona Grabowska ${ }^{1}$, Anna Stachyra ${ }^{2}$, Anna Góra - Sochacka ${ }^{2}$, Agnieszka Sirko², Agnieszka B. Olejniczak ${ }^{3}$,Zbigniew J. Leśnikowski ${ }^{4}$, Jerzy Radecki ${ }^{1}$, Hanna Radecka ${ }^{{ }^{*}}$

${ }^{1}$ Institute of Animal Reproduction and Food Research, Polish Academy of Sciences, Tuwima 10, 10-747 Olsztyn, Poland

${ }^{2}$ Institute of Biochemistry and Biophysics, Polish Academy of Sciences, Pawińskiego 5A, 02-106 Warsaw, Poland

${ }^{3}$ Screening Laboratory and ${ }^{4}$ Laboratory of Molecular Virology and Biological Chemistry, Institute of Medical Biology, Polish Academy of Sciences, 106 Lodowa St., Lodz 93-232, Poland

*Corresponding authors: Phone: +48895234636. Fax: +48895240124. E-mail: h.radecka@pan.olsztyn.pl

\section{ABSTRACT}

In this work, we report on oligonucleotide probes bearing metallacarborane [3-iron bis(dicarbollide)] redox label, deposited on gold electrode for electrochemical determination of DNA sequence derived from Avian Influenza Virus (AIV), type H5N1. The oligonucleotide probes containing 5'-terminal $\mathrm{NH}_{2}$ group were covalently attached to the electrode, via NHS/EDC coupling to carboxy-thiol SAM, previously deposited on the surface of gold. The changes in redox activity of Fe(III) centre of the metallacarborane complex before and after hybridization process was used as analytical signal. The signals generated upon hybridization with targets such as complementary or non-complementary 20-mer ssDNA or various PCR products consisting of 180-190 bp (dsDNA) were recorded by Osteryoung square-wave voltammetry (OSWV). The developed system was very sensitive towards targets containing sequence complementary to the probe with the detection limit estimated as $0.03 \mathrm{fM}(\mathrm{S} / \mathrm{N}=3.0)$ and $0.08 \mathrm{fM}(\mathrm{S} / \mathrm{N}=3)$ for 20 -mer ssDNA and for dsDNA (PCR product), respectively. The non-complementary targets generated very weak responses. Furthermore, the proposed genosensor was suitable for discrimination of PCR products with different location of the complementarity region. 
Key words: 3-iron bis(dicarbollide)-oligonucleotide, Osteryoung square-wave voltammetry, electrochemical ssDNA detection, Avian Influenza Virus (AIV)

\section{Introduction}

The electrochemical genosensors have gained strong interest in the field of monitoring of environmentally and medical relevant samples because of low equipment requirements, short time of analysis and low costs (Chang et al., 2011; Drummond et al., 2003).

Different approaches for detection of the probe-analyte hybridization processes have been applied in various genosensors. One of them is the approach based on changes in electrochemical activity of nucleobases upon the hybridization events. This concept have been proposed by Palecek and co-workers (Palecek 2009; Palecek and Bartosik, 2012). The other idea is based on changes of electrochemical parameters of the interface: electrode/aqueous solution caused by hybridization reaction (Malecka et al., 2013; Zhang et al., 2008). This category includes biosensors originally developed by Umezawa and co-workers, in which mechanism of analytical signal generation is based on ion-channel mimetic system (Umezawa et al., 2004).

One of the unfavorable feature of genosensors based on nucleobases electroactivity is rather weak analytical signals. Whereas, the ion-channel mimetic genosensors, in which the redox marker molecules are present in solutions, demand well ordered, free of pinholes monolayers deposited on the electrode surfaces, which very often is difficult to fulfill. One of the way to avoid this problem is fixing the redox molecule on the surface of the electrode. The oligonucleotide probes having the steam loop structure, modified with redox active label has been reported (Fan et al., 2003, Rai et al., 2012). As a consequence of hybridization event, self-assembled monolayer (SAMs) are characterized by precisely defined structure, more rigid in comparison with the structure of probe immobilized on the surface of electrode (Ceres et al., 2003; Gooding et al., 2003). Such a change causes increase of distance between redox active label covalently attached to the probe from the surface of electrode. In consequence, the increase of electrons transfer resistance was observed (Anne et al. 2006; Aoki et al., 2010; Farjami et al., 2011; Lai et al., 2006; Lubin et.al, 2009; Pavlovic et al., 2008; Yang et al., 2010). Such a system is called "on-off" mode of the electrochemical signal.

The most frequently used redox active labels is ferrocene (Anne et al., 2006; Aoki et al., 2010; Chatelain et al., 2012; Zhao et al., 2012; Zhuang et al., 2013) as well as methylene 
blue (Abi et al., 2012; Farjami et al., 2011; Farjami et al., 2012; Ferapontova et al., 2009; Kang et al., 2009; Kang et al., 2012; Lai et al., 2006; Liu et al., 2010; Lubin et al., 2009; Patterson et al., 2010; Pavlovic et al., 2008; Ricci et al., 2010; Yang et al., 2010). Applicability of these labels is based on their reversible redox properties in the appropriate potential windows. However, genosensors containing probes modified with ferrocene or methylene blue are not totally free from the non-specific adsorption when applied in complex media, such as for example, blood serum (Ferapontova et al., 2009).

Working in this very vivid research field, we decided to use an alternative type of redox label, namely the chemically and biologically stable complex of carborane with Fe(III) with well-defined electrochemical properties (Corsini et al., 2006; Jelen et al., 2009; Olejniczak et al., 2009; Olejniczak 2011). Metallacarboranes are vast family of metallocenetype complexes consisting of at least one carborane cage and one or more metal cations. Carborane clusters are versatile and efficient ligands for cations of metals such as $\mathrm{Co}, \mathrm{Fe}, \mathrm{Ni}$, $\mathrm{Cr}, \mathrm{Re}, \mathrm{Al}, \mathrm{Au}, \mathrm{Cu}, \mathrm{Ir}, \mathrm{Mn}, \mathrm{Pt}$, and others. This allows for incorporation of variety of metals with different properties into nucleic acids and their components. An additional advantage of metallacarboranes is susceptibility to redox potential tuning via particular derivatization of the boron cluster ligands (González-Cardoso et al., 2010; Grimes, 1982). The metallacarboranes have been applied for modification of target ssDNA (Ziółkowski et al., 2012).

Here we present the approach in which the gold electrodes were modified with oligonucleotide probe with 3-iron bis(dicarbollide) redox active complex, an alternative and probably more stable redox labels in comparison with already reported. Moreover, the novelty of the approach presented is affiliated with the attachment of the redox label at the "foot" of the oligonucleotide probe, very close to the electrode surface. To the best our knowledge, such system was not presented in the literature till now.

The new type of genosensor destined for determination of the genetic material of the H5 subtype of Avian Influenza Virus (AIV) is illustrated in Scheme 1.

\section{Scheme 1.}

(A) Chemical structure of $\mathrm{NH}_{2}$-3-iron bis(dicarbollide)-ssDNA. (B) Schematic illustration of gold electrode modification with $\mathrm{NH}_{2}$-3-iron bis(dicarbollide)-ssDNA via EDC/NHS coupling to carboxythiol SAM. 


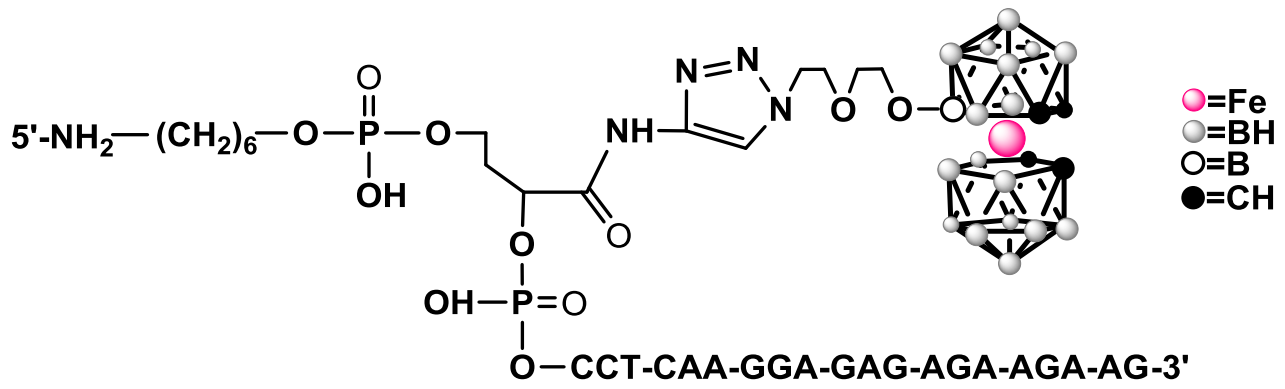

3-iron bis(dicarbollide)-oligonucleotide probe

(B)

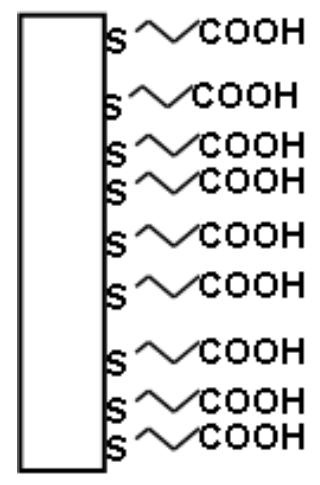

(1) EDCINHS

(2) 3-iron bis (dicarbollide)oligonucleotide probes

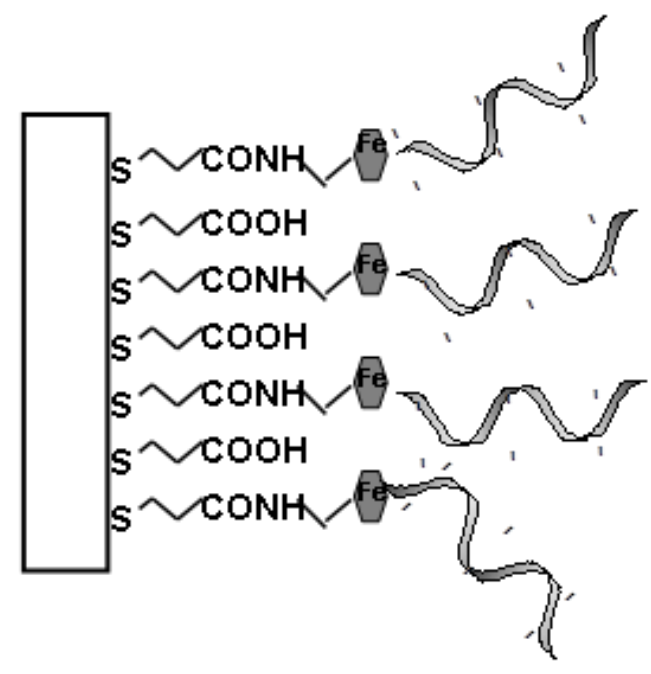

\section{Experimental}

\subsection{Reagents and materials}

3-mercaptopropionic acid $\left(\mathrm{HS}\left(\mathrm{CH}_{2}\right)_{2} \mathrm{CO}_{2} \mathrm{H}\right)$, EDC: $N$-(3-Dimethylaminopropyl)- $N$ 'ethylcarbodiimide hydrochloride $\left(\mathrm{C}_{8} \mathrm{H}_{17} \mathrm{~N}_{3} \mathrm{HCl}\right)$, NHS: $N$-Hydroxysuccinimide $\left(\mathrm{C}_{4} \mathrm{H}_{5} \mathrm{NO}_{3}\right)$, MES: 2-(N-Morpholino)ethanesulfonic acid $\left(\mathrm{C}_{6} \mathrm{H}_{13} \mathrm{NO}_{4} \mathrm{~S}\right)$, sodium perchlorate $\left(\mathrm{NaClO}_{4}\right)$, sodium chloride $(\mathrm{NaCl})$, potassium phosphate monobasic $\left(\mathrm{KH}_{2} \mathrm{PO}_{4}\right)$, trifluoroacetic acid $\left(\mathrm{CF}_{3} \mathrm{COOH}\right)$, ammonia $\left(\mathrm{NH}_{3}\right)$, ethanolamine $\left(\mathrm{NH}_{2}\left(\mathrm{CH}_{2}\right)_{2} \mathrm{OH}\right)$ were purchased from SigmaAldrich (Poznan, Poland). $\mathrm{KOH}, \mathrm{H}_{2} \mathrm{SO}_{4}$, ethanol, methanol were obtained from ABChem, 
Gliwice, Poland. All aqueous solutions were prepared with deionized and charcoal-treated water (resistivity of $18.2 \mathrm{M} \Omega \mathrm{cm}$ ) purified with a Milli-Q reagent grade water system (Millipore, Bedford, MA).

The modified oligonucleotide $\mathrm{NH}_{2}$-3-iron bis(dicarbollide)-ss-DNA (5'- $\mathrm{NH}_{2}$-CCT CAA GGA GAG AGA AGA AG-3') (provided by the Institute of Medical Biology, Polish Academy of Sciences, Łódź, Poland) was used as a probe for immobilization on a surface of gold electrodes, while two unmodified oligonucleotides, (5'-CTT CTT CTC TCT CCT TGA GG3') and nc-NC3 (5'-GGA GTT CCT CTC TCA TCA TC-3') served as complementary and non-complementary hybridization targets, respectively.

The double stranded PCR products (PCR1-PCR4) were obtained using a plasmid containing the full length $\mathrm{H} 5$ gene from the polish isolate of the influenza H5N1 virus (A/swan/Poland/305-135V08/2006; EpiFlu Database Acc No EPI156789) as a template and the following pairs of oligonucleotides as primers: 5'-GTG AAT TGG AAT ATG GTA ACT3' and 5'-CTT CTT CTC TCT CCT TGA GG-3' for PCR1, 5'-CCT CAA GGA GAG AGA AGA AG-3' and 5'-TTG GTG ACT CCA TCT ATT GC-3' for PCR2, 5'-ACA TCC ACC CTC TCA CCA-3' and 5'-CAT ACC AAC CAT CTA CCA-3' for PCR3, 5'-GGG GAC TCA ACA ATT ATG A-3' and 5'-GCT ATT TCT GAG CCC AGT-3' for PCR4. The 20-bp region complementary to the NC3 (SH-ss-DNA probe) is located at the 3'-end of PCR1, at the 5'-end of PCR2 and in the middle (83-103 bp) of PCR3. No sequence complementary to the SH-ss-DNA exists in PCR4. The total length of DNA fragments is $181 \mathrm{bp}, 179 \mathrm{bp}, 180 \mathrm{bp}$ and 183 bp for PCR1, PCR2, PCR3 and PCR4, respectively. Schematic representation of all four PCR products is shown in the Supporting Information (Scheme S1).

\subsection{Synthesis of oligonucleotide probe modified with 3-iron bis(dicarbollide)}

To the solution of oligonucleotide containing triple bond (1.0 $\mathrm{A}_{260}$ units, $0.03 \mu \mathrm{g}, 4.63$ $\mathrm{nmol}$ ) in $17.4 \mu \mathrm{L}$ of water were added TBTA (43 $\mu \mathrm{g}, 81.03 \mathrm{nmol}, 18.06 \mu \mathrm{L}$ of solution formed by dissolving of $1 \mathrm{mg}$ of TBTA in $0.42 \mathrm{~mL}$ deionized water), sodium ascorbate (23 $\mu \mathrm{g}, 115.75 \mathrm{nmol}, 4.7 \mu \mathrm{L}$ of solution formed by dissolving of $1 \mathrm{mg}$ of sodium ascorbate in $0.21 \mathrm{~mL}$ deionized water $), \mathrm{CuSO}_{4} \cdot 5 \mathrm{H}_{2} \mathrm{O}(2.89 \mu \mathrm{g}, 11.56 \mathrm{mmol}, 4.7 \mu \mathrm{L}$ of solution formed by dissolving of $1 \mathrm{mg}$ of $\mathrm{CuSO}_{4} 5 \mathrm{H}_{2} \mathrm{O}$ in $1.63 \mathrm{~mL}$ deionized water), and [8- $\mathrm{N}_{3}-$ $\left(\mathrm{CH}_{2} \mathrm{CH}_{2} \mathrm{O}\right)_{2}$-3-iron bis(dicarbollide)] (42 $\mu \mathrm{g}, 92.60 \mathrm{mmol}, 21 \mu \mathrm{L}$ of solution formed by dissolving of $1 \mathrm{mg}\left[8-\mathrm{N}_{3}-\left(\mathrm{CH}_{2} \mathrm{CH}_{2} \mathrm{O}\right)_{2}-1,2-\mathrm{C}_{2} \mathrm{~B}_{9} \mathrm{H}_{10}\right)\left(1^{\prime}, 2^{\prime}-\mathrm{C}_{2} \mathrm{~B}_{9} \mathrm{H}_{11}-3,3\right.$ ' $\left.\mathrm{Fe}\right]$ in $0.5 \mathrm{~mL}$ deionized water), and the reaction mixture was stirred at room temperature. 
After $2 \mathrm{~h}$ to the reaction mixture were added again: TBTA, sodium ascorbate, $\mathrm{CuSO}_{4} 5$ $\mathrm{H}_{2} \mathrm{O}$, and [8- $\mathrm{N}_{3}-\left(\mathrm{CH}_{2} \mathrm{CH}_{2} \mathrm{O}\right)_{2}$ 3-iron bis(dicarbollide)] in the same amounts as previously. After $2 \mathrm{~h}$ the main product was isolated and purified by reversed-phase HPLC, using the following gradient: $20 \mathrm{~min}$. from $0 \% \mathrm{D}$ to $100 \% \mathrm{D}, 5 \mathrm{~min} .100 \% \mathrm{D}, 5 \mathrm{~min}$. from $100 \% \mathrm{D}$ to $0 \%$ D. Flow rate $1 \mathrm{~mL} / \mathrm{min}$. UV detection at $\lambda=268 \mathrm{~nm}$, buffer $\mathrm{A}: \mathrm{CH}_{3} \mathrm{CN} / \mathrm{H}_{2} \mathrm{O}(2: 98$, v/v) containing 0.1 M TEAB (triethyl ammonium bicarbonate) ( $\mathrm{pH}$ 7.0), buffer $\mathrm{D}: \mathrm{CH}_{3} \mathrm{CN} / \mathrm{H}_{2} \mathrm{O}$ (40:60, v/v) containing $0.1 \mathrm{M}$ TEAB $(\mathrm{pH} 7.0)$. The fractions containing product were collected together then the solvents were evaporated under vacuum. The residue was coevaporated with $95 \%$ ethyl alcohol to remove TEAB then was dissolved in deionized water and lyophilized. RP-HPLC (conditions as above): $\mathbf{R}_{t}=15.88 \mathrm{~min}$; MALDI-TOF MS: $\mathrm{m} / z$ $(\%)=7082.16[\mathrm{M}+1](100 \%)$.

\subsection{Electrode modification}

Gold disk electrodes of $2 \mathrm{~mm}^{2}$ area (Bioanalytical Systems (BAS), West Lafayette, IN) were used for the experiments. The electrodes were polished with wet 0.3 and $0.05 \mu \mathrm{m}$ alumina slurry (Alpha and Gamma Micropolish, Buehler, Lake Bluff, IL) on a flat pad for at least $10 \mathrm{~min}$ and rinsed repeatedly with water and finally in a sonicator (30 s). The polished electrodes were then dipped in $0.5 \mathrm{M} \mathrm{KOH}$ solution deoxygenated by purging with argon for $15 \mathrm{~min}$, and the potential was cycled between -400 and $-1200 \mathrm{mV}$ (versus $\mathrm{Ag} / \mathrm{AgCl}$ reference electrode) with a scan rate of $100 \mathrm{mVs}^{-1}$ until the $\mathrm{CV}$ no longer changed. The electrochemically polished electrodes were dipped into $1 \mathrm{mM}$ solution of 3-mercaptopropionic acid in ethanol with addition of $1 \%$ trifluoroacetic acid (v/v) at room temperature for 3 hours in the tubes ( $8 \mathrm{~mm}$ diameter, with no flat bottom) sealed with Teflon tape in order to avoid the solvent evaporation. Then, the electrodes were rinsed with $10 \%$ of ammonia solution in ethanol in order to remove trifluoroacetic acid molecules from the surface. In the next step, $\mathrm{COOH}$ group present on the surface of gold electrodes were activated in EDC/NHS mixture (100 mM/50 mM respectively) during 1 hour in $0.05 \mathrm{M}$ MES buffer $\mathrm{pH}$ 5.5. Next, on the surface of gold electrodes $10 \mu \mathrm{l}$ of $10^{-5} \mathrm{M}$ solution of oligonucleotide probe $\left(\mathrm{NH}_{2}\right.$-3-iron bis(dicarbollide)-ssDNA) in 0.05 M MES buffer, $\mathrm{pH} 7.0$ were dropped, and electrodes were left in refrigerator for 48 hours under the cover. After the rinsing of modified electrodes with MES buffer $\mathrm{pH} 7.0$, they were immersed in $0.1 \mathrm{M}$ solution of ethanolamine in MES buffer $\mathrm{pH}$ 7.0 for 0.5 minute and then stored in buffer solution $\left(1 \mathrm{M} \mathrm{NaCl}, 0.1 \mathrm{M} \mathrm{NaClO}_{4}, 0.01 \mathrm{M}\right.$ 
$\mathrm{KH}_{2} \mathrm{PO}_{4}$, pH 7.0) until used. The condition involving of ethanolamine treatment was experimentally tested, and proved that it does not affect the position and value of current of the Fe(III) redox peak.

2.4. Hybridization of the 3-iron bis(dicarbollide)-oligonucleotide probe and the target sequences

The 3-iron bis(dicarbollide)-oligonucleotide probe modified gold electrode was exposed to 10 $\mu \mathrm{l}$ of the solution containing targets: 20-mer complementary or no-complementary "nocomplementary" as well as PCR products (PCR-1, PCR-2, PCR-3, PCR-4) in buffer solution as described above, for $0.5 \mathrm{~h}$ at room temperature. The samples of PCR products were heated before hybridization in a water bath at $95{ }^{\circ} \mathrm{C}$ for 10 minutes, and then rapidly cooled in an ice bath for 2 minutes. After the hybridization the electrodes were rinsed thoroughly with buffer solution and stored in the buffer at the $4{ }^{\circ} \mathrm{C}$ before electrochemical measurements.

\subsection{Electrochemical measurements}

All electrochemical measurements were performed with a potentiostat-galvanostat AutoLab (Eco Chemie, Utrecht, Netherlands) with the three-electrode configuration. Potentials were measured versus the $\mathrm{Ag} / \mathrm{AgCl}$ electrode, and a platinum wire was used as an auxiliary electrode.

Osteryoung square-wave voltammetry (OSWV) was performed with a potential scanned from $600 \mathrm{mV}$ to $-100 \mathrm{mV}$, and with a step potential of $5 \mathrm{mV}$, a square-wave frequency of $25 \mathrm{~Hz}$, and an amplitude of $50 \mathrm{mV}$.

\section{Results and discussion}

Recent reports showed, that influenza can spread rapidly and cause a range of illness among humans, therefore the early detection of this virus is highly needed, especially-because the H5 subtype is highly pathogenic (Amano et al., 2005). The detection of the influenza virus is based on non-labeling techniques, such as surface plasmon resonance (SPR) or quartz crystal microbalance (QCM) (Amano et al., 2005). However, these techniques demand quite sophisticated equipment. In comparison, the electrochemical detection offers much simpler and attractive alternative. Here, we propose 3-iron bis(dicarbollide)-oligonucleotide probes for electrochemical detection of Avian Influenza Virus (AIV) - H5N1 using Osteryoung Square-Wave Voltammetry (OSWV). 
3-Iron bis(dicarbollide) redox label was covalently attached to DNA probe using "click chemistry" methodology (El-Sagheer and Brown, 2010; Wojtczak et al., 2008) in the manner providing its location close to the surface of gold electrode. This is in contrast to redox active labels and formats reported till now.

The chemical structure of 3-iron bis(dicarbollide)-oligonucleotide probe is presented on Scheme 1A.

The genosensor sensitivity and selectivity were tested with two types of targets: 20mer ssDNA oligonucleotides and 179 - 183 base pair (bp) dsDNA fragments (PCR products), containing or not containing the region complementary to the probe, derived from the HA gene of the polish isolate of the influenza H5N1 virus (A/swan/Poland/305-135V08/2006).

\subsection{Characterization of 3-iron bis(dicarbollide)-oligonucleotide probe deposited on the gold electrode}

Scheme 1A,B illustrates the structure of the 3-iron bis(dicarbollide)-oligonucletide probe and the steps required for the gold electrode modification. The amino group containing 3-iron bis(dicarbollide)-oligonucleotide probe (Scheme 1A) was covalently attached to the surface of gold electrode by amide bond formation between carboxyl and amino groups, using EDC/NHS treatment (Scheme 1B).

Among the several parameters influencing the electron transfer kinetics of redox active self - assembled monolayers (SAMs), the distance between the redox active centre and electrode is one of the most important. The others include structure of linker connecting the redox center and electrode, as well as the molecular environment around the redox centre (Chidsey, 1991; Eckerman et al., 2010). According to the Marcus theory, parameters which influence the rate of the electron transfer are: Gibbs free energy $(\Delta \mathrm{G})$, reorganization energy $(\lambda)$, temperature $(T)$ and electronic coupling between an electron donor and acceptor $\left(\mathrm{H}_{\mathrm{AB}}\right)$. Coupling between the redox centre and electrode depends on distance and structure of the bridge, whereas, SAM composition and possibility of using different solvents have impact on the reorganization energy (Eckerman et al., 2010).

Taking into account the above mentioned parameters, in the first step, we have optimized the distance of $\mathrm{Fe}$ (III) centre from the surface of electrode in order to gain the best redox activity. The mixed thiols solution composed with 6-mercapto-1-hexanol and 10carboxy-1-decanethiol in molar ratio 100:1, respectively, have been used for formation of the $\mathrm{SAM}$ on the surface of $\mathrm{Au}$ electrode. The immobilization of $\mathrm{NH}_{2}$-3-iron bis(dicarbollide)ssDNA was achieved via EDC/HNS coupling chemistry. The value of redox current of 3-iron 
bis (dicarbollide) attached to the electrode surface, measured using Osteryoung square-wave voltammetry, was relatively small, and was in the range of $0.3 \mu \mathrm{A}$ (Figure S1, Supplementary Materials). Therefore, in order to improve the electron transfer kinetics, 3-mercaptopropionic acid SAM was applied for $\mathrm{NH}_{2}$-3-iron bis(dicarbollide)-ssDNA EDC/NHS coupling. The immobilization of $\mathrm{NH}_{2}$-3-iron bis(dicarbollide)-ssDNA in the short distance from the electrode surface increases the redox current value at least two times (Figure S1).

The cyclic voltammetry performed at the scan rate $100 \mathrm{mVs}^{-1}$ showed quasi-reversible reduction and oxidation processes of $\mathrm{Fe}(\mathrm{III})$. Two peaks at the potential $285 \mathrm{mV} \pm 5 \mathrm{mV}$ and $203 \mathrm{mV} \pm 14 \mathrm{mV}$ were observed (Figure 1, line a) which is in the range characteristic for redox system $\mathrm{Fe}(\mathrm{III}) / \mathrm{Fe}(\mathrm{II})$ (Fan et al., 2003). The linear relationship between the anodic and cathodic peak currents position $v s$ scan rate (from 10 up to $100 \mathrm{mVs}^{-1}$ ) indicates that redox process is not diffusion dependent and confirms the presence of 3-iron bis(dicarbollide)oligonucleotide probe on the surface of gold electrode (Figure S2, S3, Supplementary Materials). These results indicated also that the mercaptopropionic acid SAM is suitable for immobilization of $\mathrm{NH}_{2}$-3-iron bis(dicarbollide)-ssDNA via EDC/HNS coupling chemistry and this procedure was used for the study presented.

\section{Figure 1.}

Representative cyclic voltammograms of gold electrode modified with 3-iron bis (dicarbollide)-ssDNA (a) and after treatment with $1 \mu \mathrm{M}$ 20-mer complementary ssDNA during $1 \mathrm{~h}$ (b) Buffer conditions: $1 \mathrm{M} \mathrm{NaCl}, 0.1 \mathrm{M} \mathrm{NaClO}_{4}, 0.01 \mathrm{M} \mathrm{KH}_{2} \mathrm{PO}_{4}, \mathrm{pH} 7.0$, scan rate $100 \mathrm{mVs}^{-1}$.

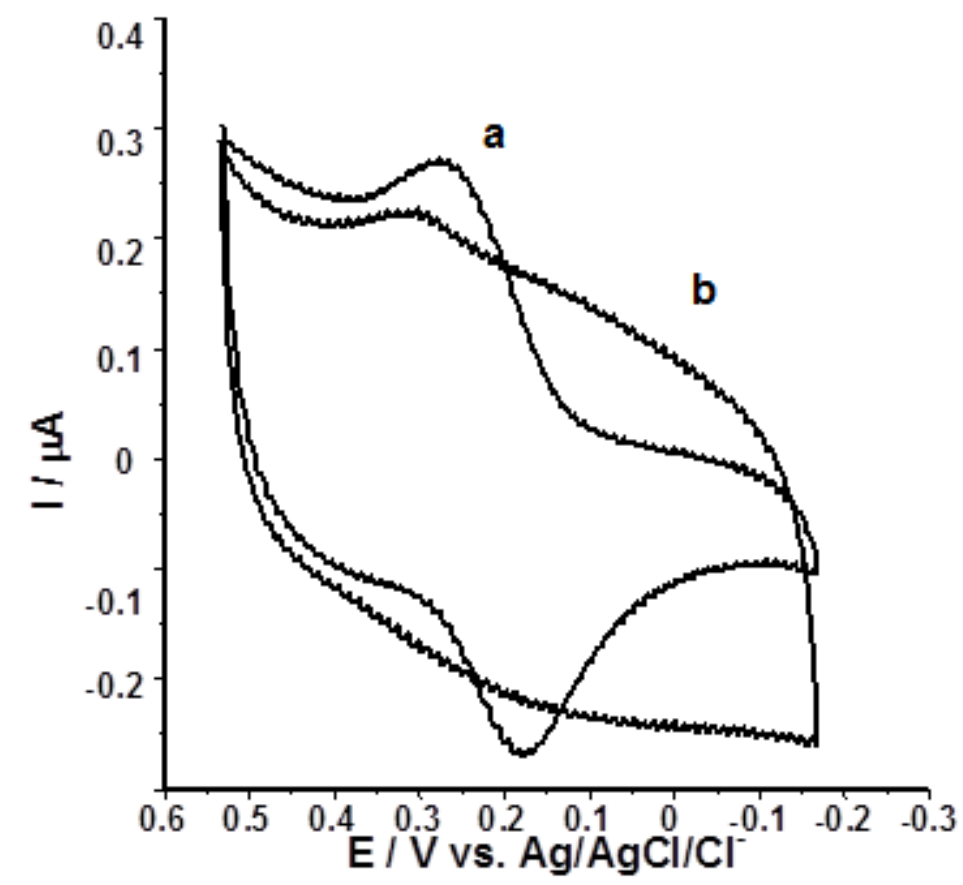


The density of DNA assembled to the Au electrode surface was calculated based on the integration of the voltammetric peaks in CV voltammograms (Figure 1) according the equation:

$$
I_{\mathrm{p}}=n^{2} F^{2} A \Gamma v / 4 R T=n F Q v / 4 R T
$$

where $\Gamma$ is the surface coverage of the redox center $\left(\mathrm{mol} \mathrm{cm}{ }^{-2}\right), A$ is the electrode area, and $Q$ is the quantity of charge $(C)$. The symbols $n, F, R$, and $T$ have their usual meaning. The obtained $\Gamma$ values of $16-32 \mathrm{pmol} \mathrm{cm}{ }^{-2}$, which represents $9.6 \times 10^{12}$ molecules $\mathrm{cm}^{-2}-1.9 \times 10^{13}$ molecules $\mathrm{cm}^{-2}$ are in good agreement with already reported (Zhuang et al., 2013).

\subsection{Selectivity of gold electrodes incorporated 3-iron bis(dicarbollide)-oligonucleotide probe} towards 20-mer ssDNA targets

To our knowledge, all reported genosensors targeting the nucleotide sequence of H5N1 Avian Influenza Virus (AIV) were based on electrochemical detection employing either electrochemical impedance spectroscopy or cyclic voltammetry with exogenous redox markers present in supporting electrolyte (Kukol et al., 2008; Liu et al., 2011; Malecka et al. 2013).

Here, we have applied a novel system, in which 3-iron bis(dicarbollide) oligonucleotide probes was fixed through the 5'-end to electrode surface modified with thiomercaptopropionic SAM. The changes of electroactivity of Fe(III) centres were used as analytical signal generated by hybridization event. The cyclic voltammetry performed at the scan rate $100 \mathrm{mVs}^{-1}$ after treatment with $1 \mu \mathrm{M} 20$-mer complementary ssDNA during $1 \mathrm{~h}$ showed decreasing of peaks coming from redox of Fe(III) (Figure 1, line b). The Osteryoung Square-Wave Voltammetry (OSWV) method was used for detection of 20-mer complementary and non-complementary oligonucleotides. The reproducibility of Osteryoung square-wave voltammograms (OSWVs) was very good. The redox current of Fe(III) centres determined in the buffer solution free of target ssDNA was in the range $0.84 \pm 0.09 \mu \mathrm{A}$, at the position of $301 \mathrm{mV} \pm 18 \mathrm{mV}$, recorded for at least 5 different modifications.

The complementary and non-complementary 20-mer ssDNAs were tested in the concentration range from $0.01 \mathrm{fM}-0.5 \mathrm{fM}$. The representative OSWV curves obtained for the gold electrode modified with 3-iron bis(dicarbollide)-oligonucletide probes in the presence of the target ssDNA are illustrated in Figure $2 \mathrm{~A}, \mathrm{~B}$. The increase of the concentration of complementary ssDNA caused the decrease of values of Fe(III) redox current assisted with 
the current peak potential shift into the negative potential direction (Figure 2A). The presence of non-complementary ssDNA sequences caused the negligible responses (Figure 2B).

\section{Figure 2.}

Representative Osteryoung square - wave voltammograms (OSWVs) obtained for electrode modified with 3-iron bis(dicarbollide)-ssDNA:

(A) after hybrydization with 20-mer complementary ssDNA in the concentrations: (a) 0.00 , (b) 0.01, (c) 0.05, (d) 0.1,(e) 0.5 [fM];

(B) after hybrydization with 20-mer non-complementary ssDNA in the concentrations: (a) 0.00, (b) 0.01, (c) 0.05 , (d) 0.1, (e) $0.5[\mathrm{fM}]$;

Buffer conditions, see Figure 1. The OSWV was performed with step potential: $5 \mathrm{mV}$, square-wave frequency: $20 \mathrm{~Hz}$ and amplitude: $50 \mathrm{mV}$.

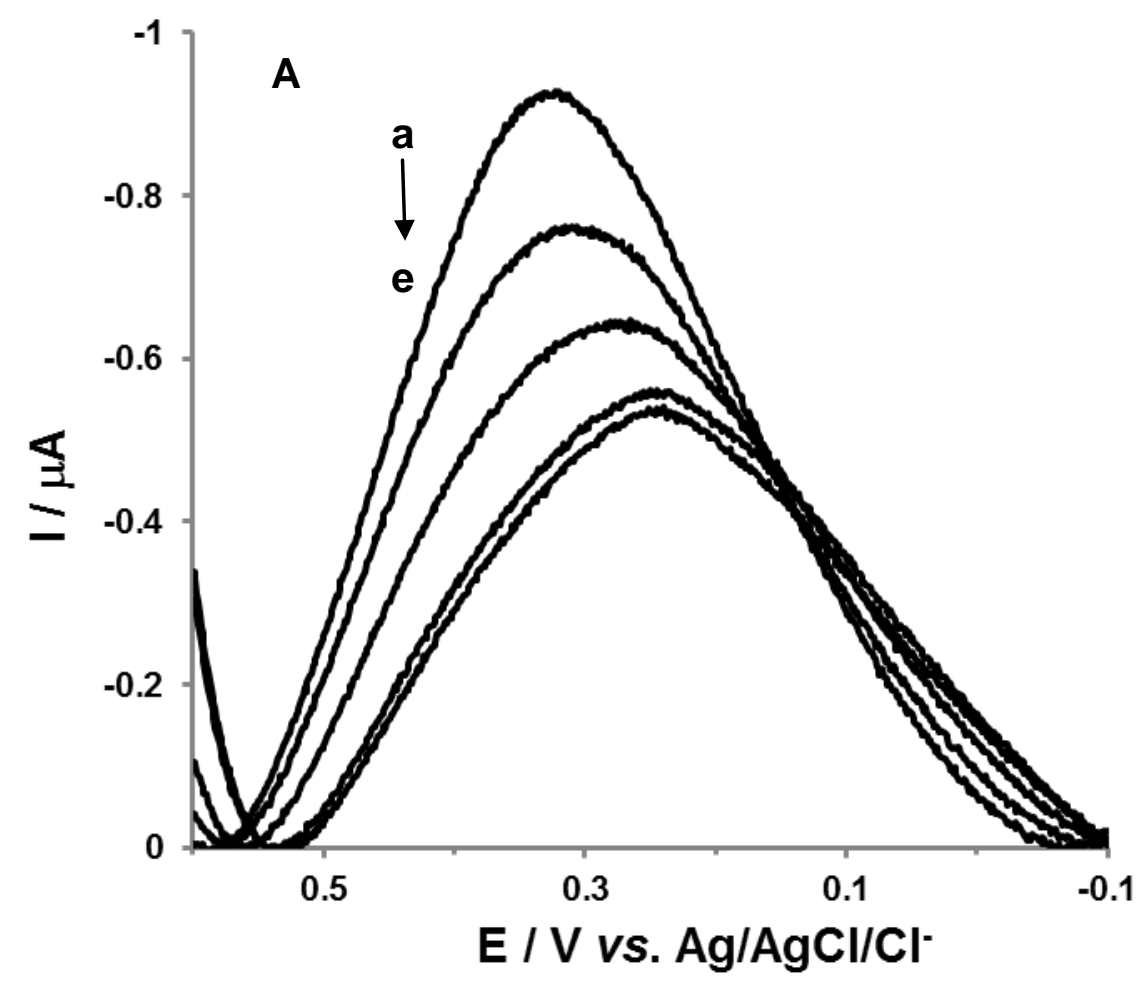




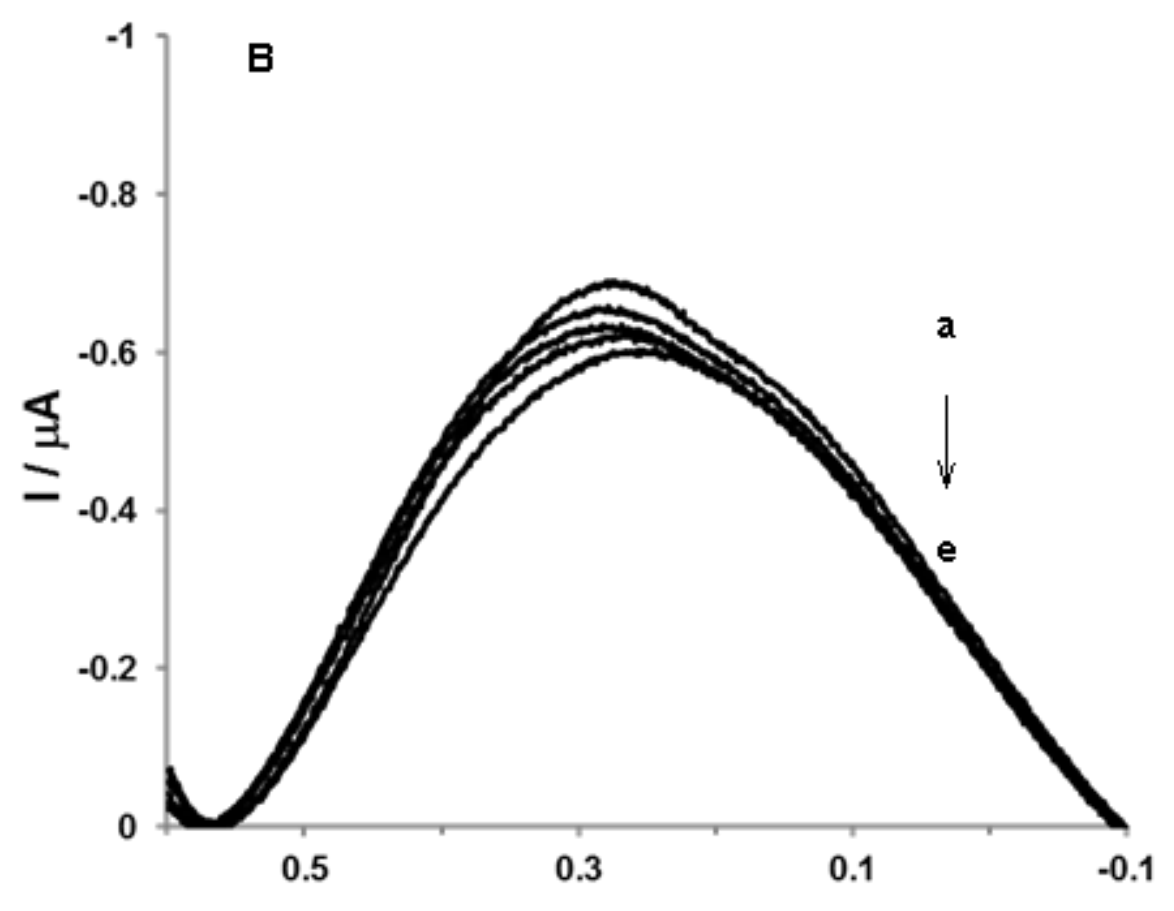

$\mathrm{E} / \mathrm{V}$ vs. $\mathrm{Ag} / \mathrm{AgCl} / \mathrm{Cl}^{-}$

The relationships of relative values of $\mathrm{Fe}(\mathrm{III})$ redox current vs ssDNA concentration are presented in Figure 3. The linear dynamic range was estimated in the concentration range $0.01 \mathrm{fM}-0.1 \mathrm{fM}$ with the calibration equation of $\left[\left(\mathrm{I}_{\mathrm{n}}-\mathrm{I}_{0}\right) / \mathrm{I}_{0}\right](\%)=-196.31 \mathrm{c}(\mathrm{fM})-11.10$ $\left(\mathrm{R}^{2}=0.9866\right)$ (Schwartz and Krull, 2012). The signal recorded at $0.5 \mathrm{fM}$ was out of linear dynamic range. The precision, defined as the closeness of agreement among individual test results, calculated based on slopes of calibration plots for complementary ssDNA was very good (Yin et al., 2013; Swartz and Krull, 2012). The relative standard deviation (RSD) of the three slopes was $4.1 \%$.

The system was very selective. At the concentration $0.1 \mathrm{fM}$, the decreasing of Fe(III) redox current $30.2 \% \pm 6.1 \%$ for the complementary ssDNA, and only $4.0 \% \pm 0.5 \%$ for noncomplementary ssDNA, were recorded (Figure 3). The detection limit was $0.03 \mathrm{fM}(\mathrm{S} / \mathrm{N}=$ $3.0)$. 


\section{Figure 3.}

The relationships between the relative intensity of redox Fe(III) current versus concentration of 20-mer complementary ssDNA $(\boldsymbol{\Delta})$ and non - complementary ssDNA $(\bullet)$. ( $\mathrm{I}_{\mathrm{n}}$ is the the value of peak current measured in the presence of particular concentration of ssDNA, and $\mathrm{I}_{0}$ is the value of peak current measured in the presence of buffer before hybridization reaction; $\mathrm{n}=3-5,0.7<\mathrm{SD}<6.1)$.

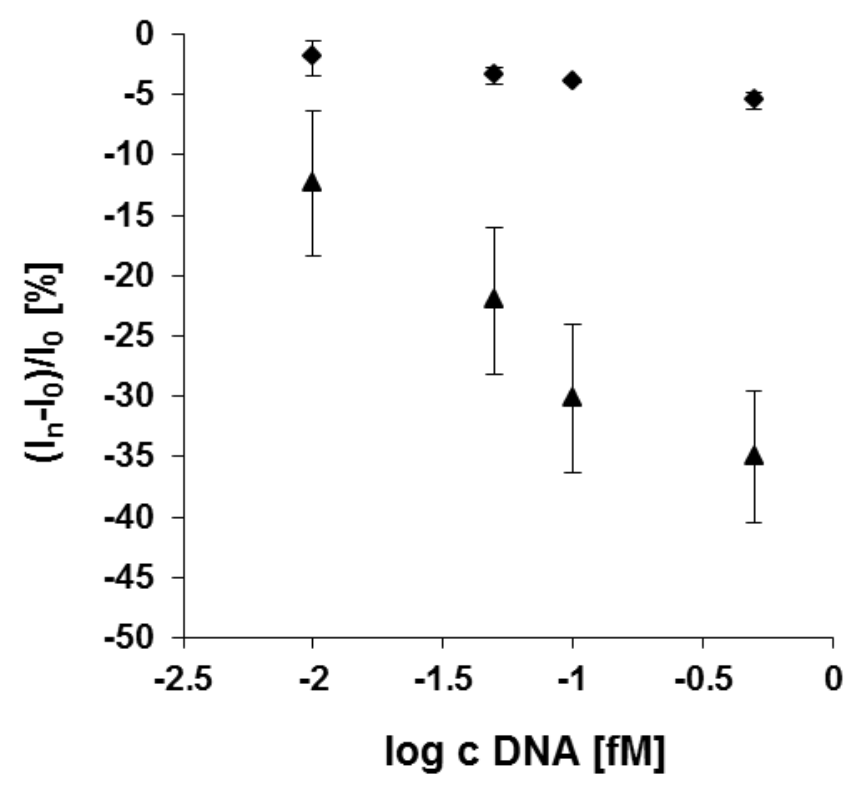

The decreasing of $\mathrm{Fe}(\mathrm{III})$ redox current was assisted also with the peak current potential shift into the negative potential direction up to $244.7 \mathrm{mV} \pm 6.4 \mathrm{mV}$ for complementary ssDNA. This means that upon the formation of the double helix, reduction/oxidation process of 3-iron bis(dicarbollide) became more irreversible due to the presence steric hindrance in the vicinity of redox centres. 
3.3. Application of gold electrode incorporated 3-iron bis(dicarbollide)-oligonucleotide probe for detection of PCR products containing complementary sequence of H5N1

Scheme S1 in the Supplementary Materials illustrates schematically the double stranded PCR products (PCR1-PCR4) used as targets in this work. PCR1, PCR2 and PCR3 have the location of the region complementary to the probe at the 3'-end, at the 5'-end and in the middle of the DNA fragment, respectively. Whereas, the PCR4 has no complementary sequences to the probe at all and was used in order to check selectivity of the genosensor. The measurement conditions, such as buffers and technique were kept the same as were applied for 20-mer ssDNA. In order to obtained the single strand DNA, the samples with PCR products were incubated in $95^{\circ} \mathrm{C}$ water baths for 10 minutes, and immediately cooled down on ice, just before the deposition on the electrode surface.

The Osteryoung square wave voltammograms were recorded at particular concentrations, for each PCR in the concentration range from $0.01 \mathrm{fM}$ to $0.5 \mathrm{fM}$. The relative changes of $\mathrm{Fe}(\mathrm{III})$ redox current observed upon hybridization processes were taken as the analytical signals (Table 1). The linear dynamic range was observed in the concentration range $0.01 \mathrm{fM}-0.1 \mathrm{fM}$ with the calibration equation of $\left[\left(\mathrm{I}_{\mathrm{n}}-\mathrm{I}_{0}\right) / \mathrm{I}_{0}\right](\%)=-147.30 \mathrm{c}(\mathrm{fM})-6.44$ $\left(\mathrm{R}^{2}=0.9974\right)$ (Swartz and Krull, 2012). The signal at the concentration $0.5 \mathrm{fM}$ was out of linear dynamic range, as was observed for 20-mer oligonucleotide. The similar changes of $\mathrm{Fe}$ (III) redox current recorded at the concentration of $0.1 \mathrm{fM}$ were observed for PCR 1 and PCR3, $21.0 \% \pm 6.2 \%$ and $20.2 \% \pm 4.0 \%$, respectively. The detection limits for both products were the same, in the range of $0.08 \mathrm{fM}(\mathrm{S} / \mathrm{N}=3.0)$. Therefore, it might be concluded that the presence of the complementary oligonucleotide sequences at the 3'-end and in the middle of the PCR products facilitates the hybridization process. The signals recorded for the PCR2 which consists the complementary to the probe oligonucleotide sequence at the 5 '-end were comparable to these observed for the PCR4 no-complementary et all (Table 1). These data indicated that proposed system is selective, allowing the discrimination of PCR products having the complementary to the probe oligonucleotide sequences in different positions. 


\section{Table 1.}

The relationships between the relative intensity of redox Fe(III) current versus concentration of tested targets $\left(I_{n}\right.$ is the value of peak current measured in the presence of particular concentration of ssDNA, and $\mathrm{I}_{0}$ is the value of peak current measured in the presence of buffer before hybridization reaction, $n=3-5)$.

\begin{tabular}{ccccc}
\hline $\begin{array}{c}\text { concentration } \\
{[\mathbf{f M}]}\end{array}$ & PCR1 & PCR2 & PCR3 & PCR4 \\
& $\begin{array}{c}\text { region } \\
\text { complementary } \\
\text { to the probe } \\
\text { at 3-end }\end{array}$ & $\begin{array}{c}\text { region } \\
\text { complementary } \\
\text { to the probe } \\
\text { at 5-end }\end{array}$ & $\begin{array}{c}\text { region } \\
\text { complementary } \\
\text { to the probe } \\
\text { in the middle }\end{array}$ & $\begin{array}{c}\text { no- } \\
\text { complementary }\end{array}$ \\
\hline 0.01 & $-7.7 \pm 3.8$ & $-10.2 \pm 3.1$ & $-8.1 \pm 3.6$ & $-6.4 \pm 2.2$ \\
0.05 & $-14.2 \pm 4.5$ & $-4.4 \pm 4.0$ & $-16.8 \pm 3.1$ & $-7.6 \pm 1.6$ \\
& & & & \\
0.1 & $-21.0 \pm 6.2$ & $-7.2 \pm 2.5$ & $-20.2 \pm 4.0$ & $-11.2 \pm 4.7$ \\
& & & & \\
0.5 & $-25.8 \pm 7.8$ & $-9.8 \pm 2.3$ & $-23.9 \pm 9.0$ & $-12.2 \pm 5.9$ \\
\hline
\end{tabular}

The precision of 3-iron bis(dicarbollide) - genosensor was estimated based on the slopes of calibration plots for PCR1 (Yin et al., 2013; Swartz and Krull, 2012). The relative standard deviation (RSD) for the four slopes in the concentration range $0.01 \mathrm{fM}-0.1 \mathrm{fM}$ was $11.7 \%$. Thus, the precision defined as the closeness of agreement among individual test results recorded for complementary PCR1 product is little worse than for 20-mer complementary sequences, but still acceptable.

The discrimination of PCR products of H5N1 virus having the complementary sequences in different locations was also achieved by us using ion-channel mimetic genosensor incorporating SH-ssDNA diluted with 6-mercaptohexan-1-ol in which the hybridization processes were traced with $\left[\mathrm{Fe}(\mathrm{CN})_{6}\right]^{-3 /-4}$ redox marker present in the sample solution (Malecka et al., 2012). This genosensor displayed detection limits in the range $10^{-11}$ 
M for the complementary 20-mer ssDNA and as well as PCR1 181-bp DNA containing 20 nucleotides complementary to the target probe at 3 -end. Whereas the detection limits recorded with the 3-iron bis(dicarbollide) - genosensor in the presence of the same DNA target were $10^{5}$ times lower, and were in the range of $10^{-16} \mathrm{M}$. On the other hand, both of them were suitable for the discrimination of the PCR product with the similar size and the complementary sequences in different locations.

\subsection{The mechanism of response of 3-iron bis(dicarbollide)-oligonucleotide genosensor towards complementary target ssDNA}

The influence of different parameters, such as potential, redox centre - electrode surface distance, solvents, temperature and nature of interfacial microenvironment on redox reactions in electroactive SAMs is a subject of numerous reports. In particular, the so called solvent effect (stabilization of one form of the redox couple relative to the another) and double layer effect (prevention of counterions from solution from entering the SAMs) were studied and described by Smith and White model (Smith et al., 1992) as well by Fawcett (Creager et al., 1997). In consequences of these effects, Gibbs free energy $(\Delta G)$ of the solvation, or spatial distribution of ions in the interfacial region could be changed (Eckerman et al., 2010; Creager et al., 1997; Smith et al., 1992).

The majority of developed recently electrochemical DNA or PNA sensors are based on phenomena of hybridization - induced conformational change in oligonucletoide probe with covalently attached redox active label at the top of the probe, either ferrocene (Anne et al., 2003; Anne et al., 2006; Aoki et al., 2007; Aoki et al., 2010; Fan et al., 2003) or methylene blue (Farjami et al., 2011; Ferapontova et al., 2009; Kang et al., 2009, Lai et al., 2006; Liu et al., 2010; Lubin et al., 2009; Patterson et al., 2010; Pavlovic et al., 2008; Ricci et al., 2007; Ricci et al., 2010; Yang et al., 2010). In such type of genosensors the rate and efficiency of charge transport is affected by changes of DNA strands flexibility. Upon the hybridization, more rigid structure is created and in consequence, the position of redox probe is changed, closer or further away from the electrode surface.

The influence of the redox label charge and the way the redox label is linked to DNA was carefully studied by Ferapontova et al. (Abi et al., 2012, Farjami et al., 2012). The authors concluded that the electron transfer kinetics in redox labeled dsDNA depends significantly on the redox label charge as well as its compatibility with the charge of the electrode. 
In the presented herein analytical approach, the faradaic signal of 3-iron bis(dicarbollide) is due to its suitable orientation on the electrode surface. This redox label is negatively charged (Olejniczak et al., 2007), whereas electrode surface at potential window applied is positively charge. So, not only close proximity of redox label to the electrode surface, but also the electrostatic attraction are the parameters which facilitate the interfacial electron rate transfer (Abi et al., 2012, Farjami et al., 2012), and well defined reduction and oxidation $\mathrm{Fe}(\mathrm{III}) / \mathrm{Fe}$ (II) was observed (Figure 1). The formation on the electrode surface the double helix structure as a result of hybridization event caused the changes in the thickness of the double layer at the interface: surface of electrode/solution analyzed. In consequence the 3iron bis(dicarbollide) centres which are attached at the bottom of the oligonucleotide probe, become more "immersed" in double helix microenvironment (Scheme 2). Moreover, the molecular environment around the redox active center become more polar, due to the increase of negative charge at the interface. The accessibility of anions present in the solution to 3-iron bis(dicarbollide) complex is restricted, in order to balance the charge. As a consequence, the electron transfer was hindered.

The similar phenomena was recently reported by Gooding et al. (Khor et al., 2011). These authors described immuno-biosensing concept based on the ferrocene redox probe attachment to the glassy carbon electrode, followed by a biotin to which anti-biotin IgG antibody is complexed. Association or dissociation of the antibody at the sensing interface caused a modulation of the ferrocene electrochemistry, due to the restriction of counter ions access the redox probe (Khor et al., 2011).

\section{Scheme 2.}

Schematic illustration of signal generation mechanism of 3-iron bis(dicarbollide) genosenor.
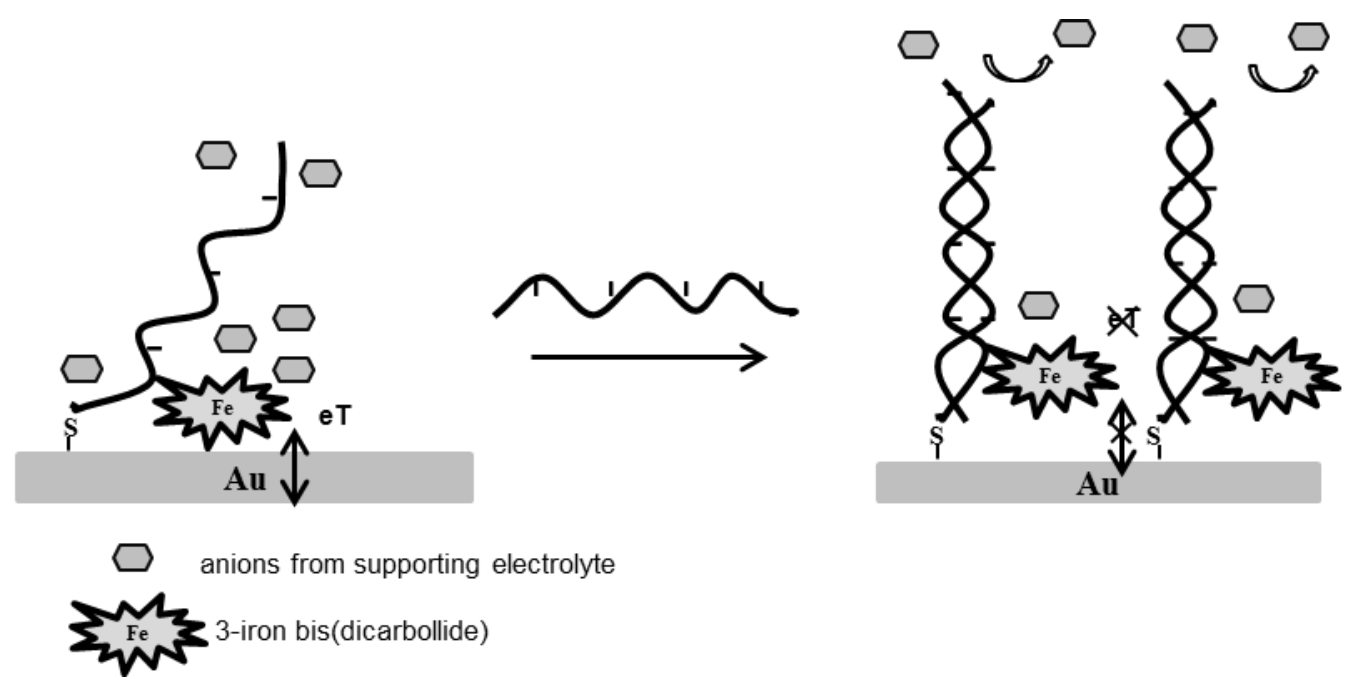


\section{CONCLUSIONS}

A novel genosensor, in which 3-iron bis(dicarbollide) redox label was attached at the "foot" of the oligonucleotide probe, very close to the electrode surface, displayed good selectivity and sensitivity towards complementary targets, 20-mer ssDNA and PCR products derived from Influenza Virus, type H5N1. The changes of electroactivity of Fe(III) centres were used as analytical signal generated by hybridization event. As a sensing technique, Osteryoung square-wave voltammetry was applied and the changes in redox activity of Fe(III) was used as analytical signal. The detection limits recorded for the 20-mer complementary ssDNA and PCR products having complementary sequences at the 3'-end and in the middle of the oligomer were equal to 0.03 and $0.08 \mathrm{fM}$, respectively, which is superior to many other already reported genosensors. An additional advantage of this genosensor is its ability to differentiate PCR products containing complementary sequence in different positions. Taking into account the above parameters, the 3-iron bis(dicarbollide) genosensor could be considered as a suitable tool for determination of the target oligonucleotide sequences derived not only from the genome of Influenza Virus, but it can be applicable also for variety of other genetic materials.

\section{Acknowledgements}

This work was supported by Innovative Economy Program, Grant No. WND-POIG.01.01.0200-007/8, Grant No N N204 531739 to ABO and ZJL, and Institute of Animal Reproduction and Food Research of Polish Academy of Sciences, Olsztyn, Poland. Partial contribution of the Statutory Fund of IMB PAS is also gratefully acknowledged.

\section{References}

Abi, A., Ferapontova, E. E., 2012. J. Am. Chem. Soc. 134, 14499-14507.

Amano, Y., Cheng, Q., 2005. Anal. Bioanal. Chem. 381, 156-164.

Aoki, H., Kitajima, A., Tao, H., 2010. Supramol. Chem. 22, 454-459.

Aoki, H., Tao, H., 2007. Analyst 132, 784-791. 
Anne, A., Bouchardon, A., Moiroux, J., 2003. J. Am. Chem. Soc. 125, 1112-1113.

Anne, A., Demaille, Ch., 2006. J. Am. Chem. Soc. 128, 542-557.

Ceres, D. M., Barton, J. K., 2003. J. Am. Chem. Soc. 125, 14964-14965.

Chatelain, G., Ripert, M., Farre, C., Ansanay-Alex, S., Chaix, C., 2012. Electrochim. Acta 59, 57-63.

Chang, H., Wang, Y., Li, J., 2011. Curr. Org. Chem. 15, 506-517.

Chidsey, C. E. D., 1991. Science 251, 919-922.

Corsini, M., Fabrizi de Biani, F., Zanello, P., 2006. Coord. Chem. Rev. 250, 1351-1372.

Creager, S. E., Rowe, G. K., 1997. J. Electroanal. Chem. 420, 291-299.

Drummond, T. G., Hill, M. G., Barton, J. K., 2003. Nat. Biotech. 21, 1192-1199.

Eckermann, A. L., Feld, D. J., Shaw, J. A., Meade, T. J., 2010. Coord. Chem. Rev. 254, 17691802.

El-Sagheer, A.H., Brown, T., 2010. Chem. Soc. Rev. 39, 1388-1405.

Fan, Ch., Plaxco, K. W., Heeger, A. J., 2003. PNAS 100, 9134-9137.

Farjami, E., Clima, L., Gothelf, K., Ferapontova, E. E., 2011. Anal. Chem. 83, 1594-1602.

Farjami, E., Campos, R., Ferapontova, E. E., 2012. Langmuir 28, 16218-16226.

Ferapontova, E. E., Gothelf, K. V., 2009. Langmuir 25, 4279-4283.

González-Cardoso, P., Stoica, A-I., Farràs, P., Pepiol, A., Viñas, C., Teixidor, F. 2010. ChemEur. J. 16, 6660-6665.

Gooding, J. J., Chou, A., Mearns, F. J., Wong, E., Jericho, K. L., 2003. Chem. Commun. 15, 1938-1939.

Grimes, R.N. Metal Interactions with Boron Clusters, Plenum Press, New York, 1982. 
Jelen, F., Olejniczak, A. B., Kourilova, A., Leśnikowski, Z. J., Palecek, E., 2009. Anal. Chem. $81,840-844$.

Kang, D., Zuo, X., Yang, R., Xia, F., Plaxco, K. W., White, R. J., 2009. Anal. Chem. 81, 9109-9113.

Kang, D., White, R. J., Xia, F., Zuo, X., Vallee-Belisle, A., Plaxco, K. W., 2012. NPG Asia Mater. 4, 1-6.

Khor, S. M., Liu, G., Fairman, C., Iyengar, S., Gooding, J. J., 2011. Biosens. Bioelectron.. 26, 2038-2044.

Kukol, A., Li, P., Esterela, P., Ko-Ferrigno, P., Migliorato, P., 2008. Anal. Biochem. 374, 143-153.

Lai, R. Y., Seferos, D. S., Heeger, A. J., Bazan, G. C., Plaxco, K. W., 2006. Langmuir 22, 10796-10800.

Liu, X., Cheng, Z., Fan, H., Ai, S., Han, R., 2011. Electrochim. Acta 56, 6266-6270.

Liu, Y., Tuleouva, N., Ramanculov, E., Revzin, A., 2010. Anal. Chem. 82, 8131-8136.

Lubin, A. A., Hunt, B. V. S., White, R. J., Plaxco, K. W., 2009. Anal. Chem. 81, 2150-2158.

Malecka, K., Grabowska, I., Radecki J., Radecka, H., Stachyra, A., Góra - Sochacka, A., Sirko, A., 2012. Electroanal. 24, 439-446.

Olejniczak, A. B., 2011. Can. J. Chem. 89, 465-470.

Olejniczak, A. B., Mucha, P., Gruner, B., Leśnikowski Z. J., 2007. Organometalics 26, 32723274.

Olejniczak, A. B., Gruner, B., Sicha, V., Broniarek, S., Leśnikowski, Z. J., 2009. Electroanal. 21, 501-506.

Palecek, E., 2009. Electroanal. 21, 239-251.

Palecek, E., Bartosik, M, 2012. Chem. Rev. 112, 3427-3481. 
Patterson, A., Caprio, F., Valle - Belisle, A., Mascone, D., Plaxco, K. W., Palleschi, G., Ricci, F., 2010. Anal. Chem. 82, 9109-9115.

Pavlovic, E., Lai, R. Y., Wu, T. T., Ferguson, B. S., Sun, R., Plaxco, K. W., Soh, H. T., 2008. Langmuir 24, 1102-1107.

Rai, V., Nyine Y. T., Hapuarachchi, H. C., Yap H. M., Ng L. Ch., Toh Ch.-S., 2012. Biosens. Bioelectron. 32, 133-140.

Ricci, F., Adornetto, G., Moscone, D., Plaxco, K. W., Palleshi, G., 2010. Chem. Commun. 46, 1742-1744.

Ricci, F., Lai, R. Y., Heeger, A. J., Plaxco, K. W., Sumner J. J., 2007a. Langmuir 23, 68276834.

Smith, Ch. P., White, H. S., 1992. Anal. Chem. 64, 2398-2405.

Swartz M. E., Krull I. S., 2012. Handbook of analytical validation. CRC Press, Taylor and Francis Group.

Umezawa, Y., Aoki, H., 2004. Anal. Chem. 76, 321A-326A.

Wojtczak, B., Andrysiak, A., Grűner, B., Lesnikowski, Z.J., 2008. Chem. Eur. J. 14, 1067510682.

Yang, K., Zhang, Ch., 2010. Anal. Chem. 82, 9500-9505.

Yin, H., Xu, Z., Wang, M., Zhang, X., Ai, S. 2013. Electrochim. Acta 89, 530-536.

Zhang, J., Lao, R., Song, S., Yan, Z., Fan, Ch., 2008. Anal. Chem. 80, 9029-9033.

Zhao, J., He, X., Bo, B., Liu, X., Yin, Y., Li, G., 2012. Biosens. Bioelectron. 34, 249-252.

Zhuang, J., Fu, L., Tang, D., Xu, M., Chen, G., Yang, H., 2013. Biosens. Bioelectron. 39, 315-319.

Ziółkowski, R., Olejniczak, A.B., Górski, Ł., Janusik, J., Leśnikowski, Z.J., Malinowska, E. 2012. Bioelectrochemistry $87,78-83$. 


\section{List of Schemes, Figures and Tables}

\section{Scheme 1.}

(A) Chemical structure of $\mathrm{NH}_{2}$-3-iron bis(dicarbollide)-ssDNA. (B) Schematic illustration of gold electrode modification with $\mathrm{NH}_{2}$-3-iron bis(dicarbollide)-ssDNA via EDC/NHS coupling to carboxythiol SAM.

\section{Scheme 2.}

Schematic illustration of signal generation mechanism of 3-iron bis(dicarbollide) genosenor.

\section{Figure 1.}

Representative cyclic voltammograms of gold electrode modified with 3-iron bis (dicarbollide)-ssDNA (a) and after treatment with $1 \mu \mathrm{M}$ 20-mer complementary ssDNA during $1 \mathrm{~h}$ (b) Buffer conditions: $1 \mathrm{M} \mathrm{NaCl}, 0.1 \mathrm{M} \mathrm{NaClO}_{4}, 0.01 \mathrm{M} \mathrm{KH}_{2} \mathrm{PO}_{4}, \mathrm{pH}$ 7.0, scan rate $100 \mathrm{mVs}^{-1}$.

\section{Figure 2.}

Representative Osteryoung square - wave voltammograms (OSWVs) obtained for electrode modified with 3-iron bis(dicarbollide)-ssDNA:

(A) after hybrydization with 20-mer complementary ssDNA in the concentrations: (a) 0.00 , (b) 0.01, (c) 0.05, (d) $0.1,(\mathbf{e}) 0.5[\mathrm{fM}]$;

(B) after hybrydization with 20-mer non-complementary ssDNA in the concentrations: (a) 0.00, (b) 0.01, (c) 0.05 , (d) 0.1, (e) $0.5[\mathrm{fM}]$;

Buffer conditions, see Figure 1. The OSWV was performed with step potential: $5 \mathrm{mV}$, square-wave frequency: $20 \mathrm{~Hz}$ and amplitude: $50 \mathrm{mV}$.

\section{Figure 3.}

The relationships between the relative intensity of redox Fe(III) current versus concentration of 20-mer complementary ssDNA $(\boldsymbol{\Delta})$ and non - complementary ssDNA $(\bullet)$. ( $\mathrm{I}_{\mathrm{n}}$ is the the value of peak current measured in the presence of particular concentration of ssDNA, and $\mathrm{I}_{0}$ is 
the value of peak current measured in the presence of buffer before hybridization reaction; $\mathrm{n}=3-5,0.7<\mathrm{SD}<6.1)$.

\section{Table 1.}

The relationships between the relative intensity of redox Fe(III) current versus concentration of tested targets $\left(I_{n}\right.$ is the value of peak current measured in the presence of particular concentration of ssDNA, and $\mathrm{I}_{0}$ is the value of peak current measured in the presence of buffer before hybridization reaction, $n=3-5$ ). 